\title{
BOM CONSELHO ÀS AVESSAS: O DESLOCAMENTO DE SENTIDO EM PROVÉRBIOS
}

Verônica Braga Birello, Raquel Tiemi Masuda Mareco

Universidade Estadual de Maringá - UEM, Pós-Graduação, Maringá, PR. E-mail: rachel.mareco@gmail.com

\section{RESUMO}

A ditadura militar marcou a sociedade brasileira não só historicamente, mas também de forma social e cultural. Muitos cidadãos tiveram seu discurso censurado na época em que o país era governado por militares. Contudo, alguns conseguiram, durante algum tempo, criticar o golpe e a violência do regime militar. Chico Buarque de Holanda foi um desses. Neste trabalho, analisamos "Bom Conselho", uma de suas canções escrita na época do regime. Para tanto, faremos o uso das teorias da Análise do Discurso francesa e seus desdobramentos no Brasil. Ao proceder com a análise, buscamos destacar os efeitos de sentido deslocados pela ressignificação dos provérbios populares utilizados por Buarque de Holanda. Assim, nos foi possível perceber que o discurso mobilizado pelo compositor está presente no interdiscurso, local onde tudo já foi dito, contudo, passa por uma reformulação e enunciação que lhe confere novos e outros efeitos de sentido.

Palavras-chave: Análise do Discurso, Ditadura militar, Ressignificação, Deslocamento, Provérbios

\section{BOM CONSELHO BY REVERSE: MEANING CHANGES IN PROVERBS}

\begin{abstract}
The military dictatorship marked the Brazilian society not only historically, but also in social and cultural forms. Many citizens had their discourses censored at the time when the country was ruled by the military. However, some have managed, for some time, to criticize the stroke and the violence of the military regime. Chico Buarque de Holanda was one of those. In this study, we analyzed "Bom Conselho", one of his songs written at the time of the regime. Therefore, we use the theories of the French Discourse Analysis and its consequences in Brazil. When proceeding with the analysis, we seek to highlight the effects of sense displaced by reframing popular sayings used by Buarque de Holanda. Thus, we were able to realize that discourse mobilized by the composer is present in interdiscourse, where everything has been said, however, it undergoes a redesign and enunciation that gives new and other effects of meaning.
\end{abstract}

Keywords: Discurse Analysis, Militar dictatorship, resignification, relocation, proverbs. 


\section{INTRODUÇÃO}

Neste artigo, desenvolvemos uma discussão sob a luz da Análise do Discurso (AD) de vertente francesa tendo como material de análise o texto da canção "Bom Conselho" de Chico Buarque de Holanda. Para este trabalho, relacionamos alguns provérbios populares em uma relação com suas apropriações e deslocamentos resultantes da composição de Chico Buarque. Para contextualizar o material escolhido para a pesquisa, ressaltamos que a canção Bom Conselho fora composta quando o país passava por um conturbado período histórico-político: a ditadura militar. Fato este que não pode ser ignorado quando voltamos nosso olhar para as músicas da MPB que emergiram nesse momento, e muito menos quando se trata de uma composição de Buarque de Holanda, símbolo da resistência musical e da musica que contestava este regime político.

Sinhori e Gomes (2010) explicam que obras literárias e composições musicais podem servir como base para pensar a realidade e o envolvimento da sociedade com a situação em que se insere. Dessa forma, entendemos que a materialidade verbal e textual pode expressar de forma simbólica parte da relação das pessoas com o contexto de produção no qual se encontram inseridas.

Estudos relacionados a essa temática, geralmente, se baseiam em textos históricos propriamente ditos, que seriam aqueles textos que tem como principal objetivo registrar para a posteridade algum fato ou situação acontecida em determinado lugar e em determinado momento. Contudo, Albuquerque Jr. (2007) comenta que a História Cultural desenvolvida a partir da segunda metade do século XX toma por base textos que não foram escritos com motivação histórica para analisar as diversas situações pelas quais os sujeitos históricos se faziam presente. 0 grande diferencial dessa vertente teórica da História Cultural é que ela se aproxima dos estudos da Análise do Discurso, visto que compreende o próprio sujeito pesquisador como um sujeito histórico e, por isso, influencia diretamente sua pesquisa. Apesar de se pretender neutro, enquanto pesquisador, percebemos que a neutralidade não existe, uma vez que o sujeito possui uma memória histórica que faz dele o que ele é.

Achard (1999) nos diz que a memória social é fruto da memória construída do historiador, sendo apenas mais uma dobra, um deslocamento do acontecimento. Sendo assim, acreditamos que seja válido tomar um objeto poético, como a letra da canção de Chico Buarque como objeto de análise linguístico e social brasileiro. No caso de nossa pesquisa escolhemos "Bom Conselho" e ressaltamos o fato da canção ter sido composta em 1972, uma vez que o regime da ditadura brasileira vai de 1964 até 1985.

"Bom Conselho" contém em seus versos alguns provérbios transformados e ressignificados a partir das condições de produção e condições de emergência da canção como critica ao regime militar. A ressignificação de tais provérbios se dá através da paródia, segundo a teoria proposta por Sant'Anna (2003), sendo assim, parece pertinente partir dos conceitos de paródia fazendo um contraponto com a paráfrase e considerando os fatores de intertextualidade que permitem o reconhecimento de certas construções dentro de outros enunciados. A paródia tornou-se particularmente popular com o advento das tecnologias que proporcionaram o livre acesso para todos os tipos de produções artísticas, sejam canônicas como modernas e até mesmo desprezadas pela critica artística vigente.

Diante do exposto, temos por objetivo construir um gesto de interpretação para as ressignificações e os deslocamentos de sentido para as estruturas destacadas na canção Bom conselho à luz da Análise do Discurso.

\section{METODOLOGIA}

A partir dessa breve contextualização histórica, acerca da composição da letra da canção, trabalharemos no sentido de identificar os provérbios que foram apropriados e deslocados em sua 
composição. Após essa identificação a análise foi embasada na teoria de Sant'Anna (2003), a fim de conceituar a paródia e a paráfrase e identificar na obra qual o procedimento utilizado, preferencialmente, por Buarque evidenciando através da materialidade textual como o processo da paródia ou paráfrase acontece em detrimento ao outro e o porquê este processo de apropriação pode ser considerado como um e não outro.

Além disso, trabalhamos com a AD francesa no sentido que de segundo Orlandi (2001) a $A D$ trabalha com a língua no mundo, com maneiras de significar por meio da produção de efeitos de sentido enquanto os sujeitos estão inseridos no meio social e produzem seus discursos em condições de produção distintas.

Neste trabalho, não trataremos da língua nem da gramática, seguindo a AD tratamos do discurso como a palavra em movimento, como uma prática que significa e se ressignifica a todo momento. Dessa forma, não propomos a separação da teoria em bloco distinto da análise com o objetivo de promover uma articulação entre ambas realizando um movimento interpretativo e analítico, na tentativa de aplicar a teoria em conjunto com a analise do corpus abordado no trabalho.

\section{RESULTADOS}

Iniciamos esta seção apresentando nosso material de análise: a canção Bom conselho.

Bom conselho

(Chico Buarque)
Ouça um bom conselho
Faça como eu digo.
que eu lhe dou de graça:
Faça como eu faço.
inútil dormir
Aja duas vezes,
que a dor não passa.
antes de pensar.
Espere sentado
Corro atrás do tempo.
ou você se cansa.
Vim de não sei onde.
Está provado,
Devagar é que
quem espera nunca alcança.
não se vai longe.
Venha, meu amigo.
Eu semeio o vento
Deixe esse regaço.
na minha cidade.
Brinque com meu fogo,
venha se queimar.
Vou pra rua
e bebo a tempestade.

Nesta canção consideramos como um dos recursos de escritura a paródia, ferramenta essa herdada pelo ocidente através dos gregos e que curiosamente surgiu a partir da música. Segundo Sant'Anna (2003), os estudos de Shipley, dizem que na antiguidade grega a paródia era executada como um "contracanto", aproximando assim as possibilidades de produção de uma música a parodia primordialmente.

Segundo Sant'Anna (2003):

Com a paródia é diferente. Aqui também, como na estilização, o autor emprega a fala de um outro; mas, em oposição à estilização, se introduz naquela outra fala uma intenção que se opõe diretamente a original. A segunda voz, depois de se ter alojado na outra fala, entra em antagonismo com a voz original que a recebeu, forçando-a a servir a fins diretamente 
opostos. A fala transforma-se num campo de batalha para interações contrárias (BAKHTIN, 1989 apud SANT'ANNA, 2003, p. 15).

Dessa forma, Buarque pode, por meio da estilização, empregar a fala do "povo" através dos provérbios populares. A sua voz, ou seja, uma segunda voz fala diretamente contra, se opondo semanticamente ao que os provérbios querem dizer e significar. Por exemplo em: "Ouça um bom conselho que the dou de graça" ele faz uma oposição com o provérbio "Se conselho fosse bom não se dava, se vendia". O compositor se apropria do enunciado popular e fala contra ele, diz que vai dar um conselho, que vai sair de graça, mas que mesmo assim é um bom conselho. Ao pensarmos nas condições de produção dos versos da canção, segundo Orlandi (2001), devemos considerar o sujeito, a situação, a memória e o contexto sócio histórico e ideológico em que se inscreve. Dessa forma, podemos pensar que o sujeito diz, ou melhor, pensa que sabe o que diz, contudo não tem acesso ao modo pelo qual os sentidos se constroem. Assim, ao usar um provérbio parodiando-o, Buarque estava tentando construir um sentido para sua composição, porém, não podia ter certeza do que aconteceria após o lançamento da música, que interpretação ela ganharia, como seria vista, uma vez que é impossível controlar o sentido de um discurso.

Ao entrar em contato com a materialidade verbal de Bom Conselho, percebemos que o conceito de paráfrase não seria aplicável a análise, considerando que, ainda segundo Sant'Anna (2003), a paráfrase não constitui um conceito de rompimento, como a música nos assinala. A paráfrase representa a continuação de uma ideia, a reformulação, porém de um mesmo conceito, ou ainda a explicação de um conceito de difícil compreensão. Contudo, como já mencionado, Buarque de Holanda faz questão de retomar os conselhos de modo a incomodar o leitor-ouvinte. No segundo verso ele diz: "Inútil dormir que a dor não passa" contrariando a expectativa do leitor que tem presente em uma memória discursiva o dizer "É só dormir que a dor passa". Ao refletir sobre uma possibilidade de significação é possível inferir a situação dos desaparecimentos da época do Al 5 decretado em 1968, em meio a tantos jovens, militantes que tinham suas casas invadidas tarde da noite e nunca mais voltaram. Não adianta dormir, não se pode dormir, isso porque todas essas formulações já circularam e determinam o que dizemos. Segundo Orlandi (2001) no interdiscurso está um saber discursivo que foi sendo construído e acumulado com o passar do tempo ao longo da história, assim tanto o provérbio que continua com o passar dos anos como a reformulação de Buarque confluíram com o eixo da atualidade e puderam emergir naquele momento, em 1972, quando a letra da canção foi escrita no auge da ditadura militar.

No segundo verso Buarque escreve: "Espere sentado ou você se cansa" e em "Está provado, quem espera nunca alcança", dois versos que dialogam diretamente com "Quem espera sempre alcança" e até com a expressão já cristalizada "Espera sentado". Nota-se que todos os provérbios utilizados no texto são formas de apropriação. Buarque, entretanto, se afasta do conceito de mimeses que tanto para Platão como para Aristóteles se apresenta sempre na retomada do belo, pois ao retomar o que está posto na cultura popular ele desdiz cada um dos provérbios, não retomando, portanto, na tentativa de imitar o ideal. Para Sant'Anna,

De uma maneira ampla pode-se dizer que as linguagens são formuladas em espaços diversos dentro do cotidiano. (...) A literatura tem a sem-cerimônia de se apropriar dessas linguagens todas. E, ao se apropriar delas, cria um espaço novo a partir do qual elas podem ser relidas. Relidas parafrásica ou parodisticamente. Mas, em qualquer dos casos, sempre haverá um desvio. Desvio mínimo ou desvio total, sempre haverá o tal desvio (SANT'ANNA, 2003, p. 66)

Nesse sentido, a literatura cria uma possibilidade de continuidade dos discursos presentes no espaço interdiscusivo. Assim, pensamos ainda no que Orlandi (2001) assevera quando diz que 
não há começo nem fim absoluto para o discurso, uma vez que existe sempre uma continuidade, uma retomada possível.

No decorrer do texto da canção, encontra-se o verso: "Brinque com meu fogo, venha se queimar" que contraria a expectativa do leitor que já possui em sua memória o ditado popular "Não brinque com fogo ou você pode se queimar". Todo individuo empiricamente sabe que queimaduras são prejudiciais à saúde, entretanto o autor pode se referir no sentido figurado a outro tipo de "brincadeira" e outro tipo de "fogo", que pode estar relacionado a uma interpretação erotizada da passagem. Contudo, pode ainda, mais provavelmente, se referir ao fogo que o cantor tinha por ideologia, sua luta contra o sistema político, se utilizarmos esse viés para interpretar as outras passagens da composição. Assim, reafirmamos que uma das características da linguagem é sua incompletude e a falta de controle sobre os sentidos produzidos.

A paródia praticada no texto pode ser considerado um avanço que acontece já desde o romantismo e que se consolida no modernismo, dentro do Brasil. Como já explicado, isso não quer dizer que a paródia seja uma novidade, pois ela já tinha sido desenvolvida na antiguidade clássica, e também na idade média. Contudo, por conta da leitura de Horácio sobre a mimese a imitação, e a paráfrase se popularizam enquanto a paródia é esquecida. Neste caso, em "Faça como eu digo. Faça como eu faço." E em "Aja duas vezes, antes de pensar." Tem-se a retomada critica de "Faça o que eu digo, mas não o que eu faço" e de "Pense duas vezes antes de agir". Em Aja duas vezes antes de pensar, ele critica a passividade, o medo excessivo das pessoas que só pensam e não fazem nada. Muitos que criticam em segredo e não tomam atitude para mudança. Buarque não participou da luta armada, por assim dizer, mas via em seu papel de cantor, de celebridade, uma função social de abrir os olhos das pessoas, para que outras pudessem realmente agir em busca de mudança.

Na estrofe formada pelos versos: "Corro atrás do tempo. Vim de não sei onde. Devagar é que não se vai longe", encontramos retomados por uma intertextualidade os provérbios: "A pressa é inimiga da perfeição" e "Devagar se vai ao longe", mobilizando, novamente, o conceito de apropriação é importante deixar claro que se trata de um deslocamento que, segundo Sant'Anna (2003), se aproxima de um estranhamento e de um desvio. Estranhamento causado pelo fato de que Buarque retira os ditados populares de sua formação discursiva e os coloca na música, e desvio porque significam de maneira diferente uma vez que ele manipula o texto original. Ele não está preocupado com a perfeição, ele corre mesmo atrás do tempo que para ele é tão precioso e que passa sem nenhuma mudança concreta. Devagar não se vai longe, devagar eles viam parentes, amigos, jovens estudantes que desapareciam aqui e ali, arrastados para a tortura iminente.

Este movimento de apropriação, de deslocamento propiciado pela paródia continua na estrofe final: "Eu semeio o vento na minha cidade. Vou pra rua e bebo a tempestade." A parodia, como já mencionado, "deforma o texto original subvertendo sua estrutura ou sentido" (SANT'ANNA, 2003, p. 41). Neste caso, percebe-se claramente a transformação do sentido dos provérbios, quando se diz: "Quem semeia vento colhe tempestade" procura-se alertar alguém de que suas atitudes trarão consequências maiores e piores, como uma tempestade, no futuro. Por sua vez, quando o compositor diz que semeia vento e vai para a rua beber a tempestade, ele não se revela nem ao menos preocupado. Ele semeia vento com seus dizeres e colhe a tempestade das revoltas estudantis, a revolta do povo brasileiro contra o regime militar que invadia as ruas das principais cidades brasileiras como uma tempestade. A tempestade é o fruto de sua plantação, sua safra de palavras. Assim, vemos os dois lados do discurso funcionando na composição do artista. Como proposto por Orlandi (2001), vemos a dispersão do discurso, dos textos e do sujeito, detectamos diversas vozes que falam por meio dos provérbios e da canção, enquanto de outro 
lado vemos a unidade do discurso e a identidade do autor, como uno, centrado, um ser homogêneo capaz de ser identificado e nomeado.

\section{DISCUSSÃO}

Este trabalho não se propôs a elaborar e conduzir uma analise única, verdadeira e incontestável da canção Bom Conselho de 1972, escrita por Chico Buarque de Holanda, pelo contrário, o objetivo foi propor e desenvolver uma análise possível, dentre as muitas possibilidades de leitura do texto. Buscou-se resgatar as condições de produção de forma com que elas também significassem por meio das escolhas do autor. Desenvolvemos uma análise interpretativa e comparativa da música com provérbios conhecidos pela população brasileira.

Além dessa abordagem analítica procuramos trabalhar os conceitos de paródia, paráfrase, mimese, apropriação, estilização e intertextualidade concretizando uma tentativa de explicar os conceitos através de exemplos práticos levando em conta que o gesto de leitura realizado prezou sempre pelo não afastamento da teoria de seu objeto de analise.

\section{CONSIDERAÇÕES FINAIS}

Nosso gesto de interpretação foi embasado nas teorias da Análise do Discurso de vertente francesa em seus desdobramentos no Brasil a fim de desvelar mais uma possibilidade de análise em linguística e literatura. Por meio de nossa análise nos foi possível perceber que o discurso mobilizado pelo compositor está presente no interdiscurso, local onde tudo já foi dito, contudo, tal discurso passa por uma reformulação e enunciação que lhe confere novos e outros efeitos de sentido. Percebemos ainda que os efeitos de sentido encontrados por nós nesse texto não são únicos e verdadeiros e que esse corpus pode ser revisitado por outros pesquisadores a fim de produzir novos gestos de leitura. Uma vez que tudo já foi dito por conta da situação de produção dessa composição pudemos interpretá-la de uma forma e não de outra nesse momento de enunciação.

\section{REFERÊNCIAS}

ACHARD, P.(et al.) Papel da Memória. Trad. José Horta Nunes. Campinas: Pontes, 1999.

ALBUQUERQUE JÚNIOR, Durval Muniz de. História: a arte de inventar o passado - ensaios de teoria da História. Bauru, SP: Edusp, 2007.

ORLANDI, E.P., Análise de Discurso: princípios e procedimentos. Campinas: Pontes, 2001.

SANT'ANNA, R. A, Paródia, Paráfrase \& Cia. 6 ed. São Paulo. Ática, 2003.

SINHORI, J., GOMES, C. A. N., Literatura testemunhal na ditadura militar: conexões entre história e literatura. Revista eletrônica Interfaces, 2010. Disponível em:

<http://revistas.unicentro.br/index.php/revista_interfaces/article/view/913> Acesso em: 28, fev,2014. 